\title{
Ovarian Metastasis of Breast Cancer Found During Ovarian Tissue Cryopreservation for Fertility Preservation: A Case Report
}

\section{Fabien KRIEF ${ }^{*}$ | Charlotte SONIG01,2,3 | Michael GRYNBERG ${ }^{1,2,3,4}$}

*Correspondence: Fabien KRIEF

Address: ${ }^{1}$ Department of Reproductive Medicine, AP-HP, Hôpital Jean Verdier, Avenue du 14 Juillet, 93140 Bondy, France; ${ }^{2}$ Department of Obstetrics-Gynecology and Reproductive Medicine, Hôpital Antoine Béclère, Clamart F-92140, France; ${ }^{3}$ Université Paris-Sud, Université Paris Saclay, Le Kremlin Bicêtre 94276, France; ${ }^{4}$ Inserm U1133 Université Paris Diderot, Paris 75013, France

e-mail $\bowtie$ : fabien.krief@hotmail.fr

Received: 11 March 2021; Accepted: 19 March 2021

Copyright: (C) 2021 KRIEF F. This is an open-access article distributed under the terms of the Creative Commons Attribution License, which permits unrestricted use, distribution, and reproduction in any medium, provided that the original work is properly cited.

\section{ABSTRACT}

We present the case of a patient with ovarian metastasis of breast cancer revealed during ovarian tissue cryopreservation for fertility preservation in an University Hospital. The patient was a twentyeight years old woman with a breast cancer had a laparoscopy for ovarian tissue cryopreservation. Ovaries revealed normal aspect on CT scan and during laparoscopy. Unexpectedly, pathological analysis of ovarian tissue revealed a breast cancer metastasis within the cortex, while the medulla was sane. This case report confirms the possible complexity of organizing optimal oncologic management and fertility preservation under time pressure.

Keywords: Oncofertility, Ovarian Tissue Cryopreservation, Breast Cancer, Ovarian Metastasis, Fertility Preservation

\section{Introduction}

Breast cancer is the most common female cancer even during the childbearing age (Ferlay et al., 2015). Thanks to prevention, diagnosis and therapeutic advances, the mortality rate of breast malignancies keeps declining (DeSantis et al., 2015). As a result, problematics related to survivors' quality of life have become a major concern (Letourneau et al., 2012). In young patients, fertility issue is in the forefront (Bloom et al., 2004). Evidence indicate that post cancer fertility is markedly decreased as a consequence of both the direct gonadal toxicity of chemotherapy regimens and the time needed before pregnancy (Bedoschi et al., 2016). In this context, oncofertility counselling is now integral part of the management of young breast cancer patients (Hashimoto et al., 2017). Recommendations state that this consultation should be organized as soon as possible following the diagnosis of malignancy (Oktay et al., 
2018). The timing before initiating cancer treatment leads to choose between oocyte or embryo vitrification after controlled ovarian stimulation, or ovarian tissue cryopreservation (OTC). Nowadays, in France, controlled ovarian hyperstimulation is often contraindicated for patients who require as soon as possible a neoadjuvant chemotherapy (Sallem et al., 2018). OTC becomes more and more used, with at least 100 births already published.

We herein report the case of a young breast cancer patient in whom urgent OTC was performed, finally revealing the presence of unexpected ovarian metastasis.

\section{Case Presentation}

The case report is from the department of reproductive medicine, Hospital Jean Verdier, Bondy, France. Institutional review board approval was not required by the institution. The patient was a 28year-old female who was diagnosed with grade 2 invasive ductal breast carcinoma. Her personal medical history included one abortion. She reported no family history of cancer. Estrogen or progesterone receptors, nor HER2 were highly expressed. The brain, thoracic abdominal and pelvic CT scans did not find any metastasis. The patient was then referred to an oncologic hospital. Physical examination revealed a lump of the whole right breast, with redness and extension to the chest wall. There were also right metastatic lymph nodes and 2 other suspect lumps in the left breast. Biopsies of both breasts confirmed the initial diagnosis. A whole-body PET scan was scheduled but was not available before 10 days.

According to the French recommendations, the patient was referred for oncofertility counselling before the initiation of cancer treatment (APHP, 2018). Markers of the follicular ovarian status measured on cycle day 12 revealed reduced ovarian reserve with serum AMH levels at $0.6 \mathrm{ng} / \mathrm{mL}$ and 7 small antral follicles counted on both ovaries. After counselling, due to the timing of chemotherapy and the neoadjuvant situation, ovarian tissue cryopreservation (OTC) was the chosen option. In our routine practice, we offer this technique in combination with oocyte vitrification after in vitro maturation (IVM). After informed consent, the patients opted for IVM combined with OTC and further administration of GnRH analogues during chemotherapy.

Laparoscopic right oophorectomy after transvaginal immature oocyte retrieval was then performed. The ovary looked macroscopically normal. No complication had been reported after the surgical procedure and 4 matures eggs as well as 22 strips of ovarian cortex were cryopreserved. Unexpectedly, pathological analysis of ovarian tissue revealed a breast cancer metastasis within the cortex, while the medulla was clear. The final stage of the cancer was T4cN2M1 based on the PET Scan. Despite chemotherapy, the patient did not respond to treatment and died 6 months later. 


\section{Discussion}

Fertility preservation is nowadays an integral part of the initial management of young cancer patients. Among Fertility Preservation techniques available in pubertal women, oocyte vitrification following controlled ovarian hyperstimulation represents the most established and efficient method (Committee of American Society for Reproductive Medicine, 2013). However, OTC may also represent a more and more realistic option, even if the transplantation is still considered experimental (Donnez and Dolmans, 2017). The diagnosis of cancer often implies relatively urgent treatment. Therefore, fertility preservation represents a race against time. Whatever the technique chosen it is important to eliminate the presence of malignant cells within the ovary. In addition, when OTC is performed, the risk will be at the time transplantation with possible reintroduction of cancer cells and further recurrence of the primary disease. The main risk factors of ovarian metastases are a tumor $>5 \mathrm{~cm}$, inflammatory breast cancer, and the time frame between breast cancer diagnosis and oophorectomy (Peters et al., 2017). Therefore, this patient should have been considered at risk for ovarian tissue grafting.

Apart from these oncologic risks, oncofertility also needs balancing the benefit and risks of FP techniques especially in case of life-threatening diseases and poor prognosis (Lambertini et al., 2017; Partridge et al., 2010).

The present case report points out many key questions in oncofertility. The time pressure for both oncologists and gynecologists led to organize the oncofertility counselling and urgent OTC before the final assessment of tumor extension. If the cancer stage was known before the oncofertility counselling, we could have avoided this surgery procedure.

Although the diagnosis of ovarian metastasis remains crucial, it may represent a difficult issue. Indeed, ovarian metastases are typically solitary and most often clinically asymptomatic (Peters et al., 2017). These characteristics, and their disappearance with chemotherapy, may explain that the prevalence is probably underestimated. They appear most of the time years after the initial disease (Peters et al., 2017; Bigorie et al., 2010; Pimentel et al., 2016). The prevalence of ovarian metastases of breast cancer is estimated between 13 and 47\% on postmortem analysis (Bigorie et al., 2010; Perrotin et al., 2001; Bastings et al., 2013). However, a recent study conducted in The Netherlands, found 2.4\% of ovarian metastases in oophorectomies performed in breast cancer patients aged less than 41 years old. Thus, the risk of having malignant cells in ovarian tissue recovered for cryopreservation remains very low (Bastings et al., 2013). A limitation for drawing such a conclusion could be the limited number of samples analyzed before cryopreservation. Data from patients having undergone ovarian tissue transplantation confirms the very low risk with only one local recurrence, probably independent from the graft 
(Rosendahl et al., 2011). With advances in in vitro follicular growth, the graft will not be mandatory anymore for restoring fertility. Therefore, tracking ovarian metastases will probably become more obsolete.

\section{Conclusion}

Fertility preservation represents an important issue for young women diagnosed with cancer. However, both oncologists and specialist in reproductive medicine are submitted to an extreme time pressure, which could sometimes lead to unexpected suboptimal management.

\section{Conflict of Interest: None}

Authorship: F.K. participated in the collection of data and contributed to writing the manuscript. C.S. was involved in the collection of data, the design of the study and contributed to revising the manuscript. M.G. participated in the design of the study, collection of data, and critical revision of the manuscript.

\section{References}

APHP. Référentiel de Préservation de la Fertilité. 2018. Disponible sur: https://www.aphp.fr/contenu/referentielpreservation-de-la-fertilite-feminine

Bastings L, Beerendonk CC, Westphal JR, Massuger LF, Kaal SE, Van Leeuwen FE, Braat DD, Peek R. Autotransplantation of cryopreserved ovarian tissue in cancer survivors and the risk of reintroducing malignancy: A systematic review. Human reproduction update 2013 ; $19: 483-506$.

Bedoschi G, Navarro PA, Oktay K. Chemotherapy-induced damage to ovary: mechanisms and clinical impact. Future Oncol 2016; $12: 2333-2344$.

Bigorie V, Morice P, Duvillard P, Antoine M, Cortez A, Flejou JF, Uzan S, Darai E, Barranger E. Ovarian metastases from breast cancer. Cancer 2010; 116: 799-804.

Bloom JR, Stewart SL, Chang S, Banks PJ. Then and now: quality of life of young breast cancer survivors. Psychooncology 2004; 13: 147-160.

DeSantis CE, Bray F, Ferlay J, Lortet-Tieulent J, Anderson BO, Jemal A. International Variation in Female Breast Cancer Incidence and Mortality Rates. Cancer Epidemiol Biomarkers Prev 2015; 24:1495-506.

Donnez J and Dolmans MM. Fertility Preservation in Women. Campion EW, éditeur. N Engl J Med 2017; 377: $1657-1665$.

Ferlay J, Soerjomataram I, Dikshit R, Eser S, Mathers C, Rebelo M, et al. Cancer incidence and mortality worldwide: sources, methods and major patterns in GLOBOCAN 2012. Int J Cancer 2015; 136: E359-E386.

Hashimoto T, Nakamura Y, Obata R, Doshida M, Toya M, Takeuchi T, Kyono K. Effects of fertility preservation in patients with breast cancer: A retrospective two-centers study. Reprod Med Biol 2017; 16: 374-379.

Lambertini M, Goldrat O, Clatot F, Demeestere I, Awada A. Controversies about fertility and pregnancy issues in young breast cancer patients: current state of the art. Curr Opin Oncol 2017; 29: 243-252. 
Letourneau JM, Ebbel EE, Katz PP, Katz A, Ai WZ, Chien AJ, Melisko ME, Cedars MI, Rosen MP. Pretreatment fertility counseling and fertility preservation improve quality of life in reproductive age women with cancer. Cancer 2012; 118: $1710-1717$.

Oktay K, Harvey BE, Partridge AH, Quinn GP, Reinecke J, Taylor HS, Wallace WH, Wang ET, Loren AW. Fertility Preservation in Patients with Cancer: ASCO Clinical Practice Guideline Update. J Clin Oncol Off J Am Soc Clin Oncol 2018; 36: 1994-2001.

Partridge AH, Ruddy KJ, Gelber S, Schapira L, Abusief M, Meyer M, Ginsburg E. Ovarian reserve in women who remain premenopausal after chemotherapy for early stage breast cancer. Fertil Steril 2010; 94: 638-644.

Perrotin F, Marret H, Bouquin R, Fischer-Perrotin N, Lansac J, Body G. Incidence, diagnosis and prognosis of ovarian metastasis in breast cancer. Gynecol Obstet Fertil 2001; 29: 308-315.

Peters IT, van der Steen MA, Huisman BW, Hilders CG, Smit VT, Vahrmeijer AL, Sier CF, Trimbos JB, Kuppen PJ. Morphological and phenotypical features of ovarian metastases in breast cancer patients. BMC Cancer 2017; $17: 206$.

Pimentel C, Becquet M, Lavoue V, Henno S, Leveque J, Ouldamer L. Ovarian Metastases from Breast Cancer: A Series of 28 Cases. Anticancer Res 2016; 36: 4195-4200.

Practice Committee of American Society for Reproductive Medicine. Fertility preservation in patients undergoing gonadotoxic therapy or gonadectomy: a committee opinion. Fertil Steril 2013; 100: 1214-1223.

Rosendahl M, Schmidt KT, Ernst E, Rasmussen PE, Loft A, Byskov AG, Andersen AN, Andersen CY. Cryopreservation of ovarian tissue for a decade in Denmark: a view of the technique. Reprod Biomed Online 2011; 22: 162-171.

Sallem A, Shore J, Ray-Coquard I, Ferreux L, Bourdon M, Maignien C, Patrat C, Wolf JP, Pocate-Cheriet K. Fertility preservation in women with cancer: a national study about French oncologists awareness, experience, and feelings. J Assist Reprod Genet 2018; 35: 1843-1850. 